Research Article

\title{
Strong Convergence Theorems for Common Fixed Points of an Infinite Family of Asymptotically Nonexpansive Mappings
}

\author{
Yuanheng Wang \\ Department of Mathematics, Zhejiang Normal University, Zhejiang 321004, China \\ Correspondence should be addressed to Yuanheng Wang; wangyuanhengmath@163.com
}

Received 13 March 2014; Accepted 31 May 2014; Published 16 June 2014

Academic Editor: Chong Li

Copyright @ 2014 Yuanheng Wang. This is an open access article distributed under the Creative Commons Attribution License, which permits unrestricted use, distribution, and reproduction in any medium, provided the original work is properly cited.

In the framework of a real Banach space with uniformly Gateaux differentiable norm, some new viscosity iterative sequences $\left\{x_{n}\right\}$ are introduced for an infinite family of asymptotically nonexpansive mappings $\left\{T_{i}\right\}_{i=1}^{\infty}$ in this paper. Under some appropriate conditions, we prove that the iterative sequences $\left\{x_{n}\right\}$ converge strongly to a common fixed point of the mappings $\left\{T_{i}\right\}_{i=1}^{\infty}$, which is also a solution of a variational inequality. Our results extend and improve some recent results of other authors.

\section{Introduction}

Let $E$ be a real Banach space, $C$ a nonempty subset of $E$, and $T: C \rightarrow C$ a nonlinear mapping. Denote by $F(T)$ the set of fixed points of $T$. Recall that $T$ is said to be nonexpansive, if

$$
\|T x-T y\| \leq\|x-y\|, \quad \forall x, y \in C .
$$

$T$ is said to be contraction, if there exists a constant $\alpha \in(0,1)$, such that

$$
\|T(x)-T(y)\| \leq \alpha\|x-y\|, \quad \forall x, y \in C .
$$

We use $\prod_{C}$ to denote the collection of all contractions on $C$.

$T$ is said to be asymptotically nonexpansive, if there exists a sequence $h_{n} \subseteq[1, \infty)$ with $h_{n} \rightarrow 1$ as $n \rightarrow \infty$ such that

$$
\left\|T^{n} x-T^{n} y\right\| \leq h_{n}\|x-y\|, \quad \forall x, y \in C .
$$

$\left\{T_{i}\right\}_{i=1}^{\infty}$ is said to be uniform Lipschitzian with the coefficient $L$, if for any $i=1,2, \ldots$, there holds

$$
\left\|T_{i}^{n} x-T_{i}^{n} y\right\| \leq L\|x-y\|, \quad \forall x, y \in C .
$$

It is clear that the class of contraction mappings must be included in the class of nonexpansive mappings and the class of nonexpansive mappings in that of asymptotically nonexpansive mappings.

The class of asymptotically nonexpansive mappings was introduced by Goebel and Kirk [1] in 1972. They proved that if $C$ is a nonempty bounded closed convex subset of a uniformly convex Banach space $E$, then every asymptotically nonexpansive self-mapping $T$ has a fixed point in $C$. Further, the set $F(T)$ of fixed points of $T$ is closed and convex.

In 2001, Khan and Takahasi [2] used the modified Ishikawa process to approximate common fixed points of two asymptotically nonexpansive mappings. In 2003, Sun [3] studied an implicit iterative scheme initiated by $\mathrm{Xu}$ and Ori [4] for a finite family of asymptotically quasi-nonexpansive mappings. Shahzad and Udomene [5], in 2006, proved some convergence theorems for the modified Ishikawa iterative process of two asymptotically quasi-nonexpansive mappings to a common fixed point. Shahzad and Zegeye [6] introduced a new concept of generalized asymptotically nonexpansive mappings and proved some strong convergence theorems for fixed points of finite family of this class. In 2008, Khan et al. [7] introduced an iterative sequence for a finite family of asymptotically quasi-nonexpansive mappings in Banach spaces. Meanwhile, Zhao [8] proved the following conclusion.

Let $E$ be a uniformly smooth Banach space, $f \in \prod_{C}$, and let $T_{1}, T_{2}, \ldots, T_{N}$ be a finite family of nonexpansive mappings 
from $C$ into itself, such that the set $\bigcap_{i=1}^{N} F\left(T_{i}\right)$ is nonempty. Under some sufficient conditions, the iterative sequence $\left\{x_{n}\right\}$ defined by (5) converges strongly to a common fixed point of $T_{1}, T_{2} \ldots, T_{N}$. Consider

$$
\begin{gathered}
y_{n}=\beta_{n+1} x_{n}+\left(1-\beta_{n+1}\right) T_{n+1} x_{n}, \quad n \geq 0, \\
x_{n+1}=\alpha_{n+1} f\left(x_{n}\right)+\left(1-\alpha_{n+1}\right) T_{n+1} y_{n}, \quad n \geq 0 .
\end{gathered}
$$

Common fixed points of nonlinear mappings play an important role in solving systems of equations and inequalities. Many researchers [9-19] are interested in studying approximation method for finding common fixed points of nonlinear mapping in recent years.

Motivated and inspired by the above results, in this paper, for an infinite family of asymptotically nonexpansive mappings $\left\{T_{i}\right\}_{i=1}^{\infty}$ from $C$ into itself, we introduce a new viscosity iterative process $\left\{x_{n}\right\}$ defined by

$$
\begin{gathered}
y_{n}=\beta_{n} x_{n}+\left(1-\beta_{n}\right) T_{i}^{n} x_{n}, \quad n \geq 0, \\
x_{n+1}=\alpha_{n} f\left(x_{n}\right)+\left(1-\alpha_{n}\right) y_{n}, \quad n \geq 0 .
\end{gathered}
$$

Under appropriate conditions on $C, T_{i},\left\{\alpha_{n}\right\}$, and $\left\{\beta_{n}\right\}$ in $(0,1)$, we prove that the $\left\{x_{n}\right\}$ converges strongly to $\widehat{x} \in F$, which is also a solution of the following variational inequality:

$$
\langle\widehat{x}-f(\widehat{x}), J(\widehat{x}-p)\rangle \leq 0, \quad \forall p \in F .
$$

Our results extend and improve some results of other authors (e.g., see $[8,17,19])$ from nonexpansive mappings to the more general class of asymptotically nonexpansive mappings and from finite family mappings to infinite family mappings.

\section{Preliminaries}

In order to prove our results, we need the following definitions and lemmas.

Assume that $E$ is a real Banach space and $E^{*}$ is the dual space of $E$. by

$J: E \rightarrow 2^{E^{*}}$ is the normalized duality mapping defined

$$
J(x)=\left\{f \in E^{*}:\langle x, f\rangle=\|x\|^{2}=\|f\|^{2}\right\}, \quad x \in E .
$$

The space $E$ is said to be with Gateaux differentiable norm, if the limit

$$
\lim _{t \rightarrow 0} \frac{\|x+t y\|-\|x\|}{t}
$$

exists for each $y$ and any $x$ in its unit sphere $U=\{x \in E$ : $\|x\|=1\}$.

In a Banach space $E$ whose norm is uniformly Gateaux differentiable, the duality mapping $J$ is single-valued and norm-to-weak ${ }^{*}$ uniformly continuous on any bounded sets of $E$.

Lemma 1 (see [18]). In a Banach space E, there holds the inequality

$$
\begin{array}{r}
\|x+y\|^{2} \leq\|x\|^{2}+2\langle y, j(x+y)\rangle, \quad \forall x, y \in C, \\
\text { where } j(x+y) \in J(x+y) .
\end{array}
$$

Lemma 2 (see [20]). Let $\left\{\alpha_{n}\right\}_{n=0}^{\infty}$ be a sequence of nonnegative real numbers satisfying the property

$$
\alpha_{n+1} \leq\left(1-\gamma_{n}\right) \alpha_{n}+\gamma_{n} \delta_{n}, \quad n \geq 0
$$

where $\left\{\gamma_{n}\right\} \subset(0,1)$ and $\left\{\delta_{n}\right\}$ are two sequences such that

$$
\begin{aligned}
& \text { (1) } \lim _{n \rightarrow \infty} \gamma_{n}=0, \quad \sum \gamma_{n}=\infty ; \\
& \text { (2) } \limsup _{n \rightarrow \infty} \delta_{n} \leq \quad\left(\text { or } \sum\left|\mu_{n} \delta_{n}\right|<\infty\right) .
\end{aligned}
$$

Then $\lim _{n \rightarrow \infty} \alpha_{n}=0$.

In order to prove the main results of this paper, the following lemmas should be used.

Lemma 3 (see [21]). Let $\left\{x_{n}\right\},\left\{y_{n}\right\}$ be bounded sequences in a Banach space $X,\left\{\alpha_{n}\right\} \subset[0,1]$, satisfying $0<\liminf _{n \rightarrow \infty} \alpha_{n} \leq$ $\limsup _{n \rightarrow \infty} \alpha_{n}<1$, and suppose

$$
\begin{aligned}
& \text { (1) } x_{n+1}=\alpha_{n} x_{n}+\left(1-\alpha_{n}\right) y_{n} \text {; } \\
& \text { (2) } \limsup _{n \rightarrow \infty}\left(\left\|y_{n+1}-y_{n}\right\|-\left\|x_{n+1}-x_{n}\right\|\right) \leq 0 .
\end{aligned}
$$

Then $\lim _{n \rightarrow \infty}\left\|y_{n}-x_{n}\right\|=0$.

\section{Main Results}

Now, we are ready to give the main results.

Theorem 4. Let $K$ be a nonempty closed convex subset of a real Banach space E with uniformly Gateaux differentiable norm. Let $\left\{T_{i}\right\}_{i=1}^{\infty}$ be an infinite family of asymptotically nonexpansive mappings with the coefficients $h_{\text {in }}: \lim _{n \rightarrow \infty} h_{\text {in }}=1$ and uniform Lipschitzian with the coefficient L from $K$ into itself, $F=\bigcap_{i=1}^{\infty} F\left(T_{i}\right) \neq \varnothing$ and $f \in \prod_{K}$ with the coefficient $\alpha$. Assume that the sequences $\left\{\alpha_{n}\right\},\left\{\beta_{n}\right\} \in(0,1)$ satisfy the following conditions:

$$
\begin{aligned}
& \text { (C1) } \sum_{n=1}^{\infty} \alpha_{n}=\infty, \lim _{n \rightarrow \infty} \alpha_{n}=0 ; \\
& \text { (C2) } 0<\lim \inf _{n \rightarrow \infty} \beta_{n} \leq \lim \sup _{n \rightarrow \infty} \beta_{n}<1 \text {; } \\
& \text { (C3) } h_{\text {in }}-1=o\left(\alpha_{n}\right) .
\end{aligned}
$$

Then the sequence $\left\{x_{n}\right\}$ defined by (6) converges strongly to $\widehat{x} \in F$ if and only if, for any $i, \lim _{n \rightarrow \infty}\left\|T_{i} x_{n}-x_{n}\right\|=0$ holds. And $\widehat{x}$ is a solution of the following variational inequality:

$$
\langle\widehat{x}-f(\widehat{x}), J(\widehat{x}-p)\rangle \leq 0, \quad \forall p \in F
$$

Proof.

Sufficiency. The sufficient proof is divided into five steps. 
Step 1. We observe that $\left\{x_{n}\right\}$ is bounded. Indeed, let $a_{n}=\beta_{n}+$ $\left(1-\beta_{n}\right) h_{i n}, a=\sup \left\{a_{n}\right\}, b=\inf \left\{a_{n}\right\}=1$. Taking a fixed point $p$ of $F$, we have

$$
\begin{aligned}
& \left\|y_{n}-p\right\| \\
& \leq \beta_{n}\left\|x_{n}-p\right\|+\left(1-\beta_{n}\right)\left\|T_{i}^{n} x_{n}-p\right\| \\
& \leq a_{n}\left\|x_{n}-p\right\| \text {, } \\
& \left\|x_{n+1}-p\right\| \\
& \leq \alpha_{n}\left\|f\left(x_{n}\right)-f(p)\right\|+\alpha_{n}\|f(p)-p\| \\
& +\left(1-\alpha_{n}\right)\left\|y_{n}-p\right\| \\
& \leq \alpha_{n} \alpha\left\|x_{n}-p\right\|+\left(1-\alpha_{n}\right) a_{n}\left\|x_{n}-p\right\|+\alpha_{n}\|f(p)-p\| \\
& =\left(a_{n}-\left(a_{n}-\alpha\right) \alpha_{n}\right)\left\|x_{n}-p\right\|+\alpha_{n}\left(a_{n}-\alpha\right) \frac{\|f(p)-p\|}{a_{n}-\alpha} \\
& \leq a_{n} \max \left\{\left\|x_{n}-p\right\|, \frac{\|f(p)-p\|}{a_{n}-\alpha}\right\} .
\end{aligned}
$$

Using an introduction, we have

$$
\left\|x_{n}-p\right\| \leq a \max \left\{\left\|x_{0}-p\right\|, \frac{\|f(p)-p\|}{b-\alpha}\right\} .
$$

Hence, $\left\{x_{n}\right\}$ is bounded so are the sets $\left\{y_{n}\right\},\left\{f\left(x_{n}\right)\right\}$ and $\left\{T_{i}^{n} x_{n}\right\}$.

Step 2. We claim that $\lim _{n \rightarrow \infty}\left\|x_{n+1}-x_{n}\right\|=0$. Setting $l_{n}=$ $\left(1-\alpha_{n}\right) \beta_{n}, n \geq 1$, it follows from (C1) and (C2) that

$$
0<\liminf _{n \rightarrow \infty} l_{n} \leq \limsup _{n \rightarrow \infty} l_{n}<1 .
$$

Define $x_{n+1}=l_{n} x_{n}+\left(1-l_{n}\right) z_{n}$, and observe that

$$
\begin{aligned}
& z_{n+1}-z_{n} \\
& =\frac{x_{n+2}-l_{n+1} x_{n+1}}{1-l_{n+1}}-\frac{x_{n+1}-l_{n} x_{n}}{1-l_{n}} \\
& =\left[\left(\alpha_{n+1} f\left(x_{n+1}\right)\right.\right. \\
& \left.\quad+\left(1-\alpha_{n+1}\right)\left(\beta_{n+1} x_{n+1}+\left(1-\beta_{n+1}\right) T_{i}^{n+1} x_{n+1}\right)\right) \\
& \quad \times\left(1-l_{n+1}\right)^{-1} \\
& \left.\quad-\frac{l_{n+1} x_{n+1}}{1-l_{n+1}}\right] \\
& \quad-\frac{\alpha_{n} f\left(x_{n}\right)+\left(1-\alpha_{n}\right)\left(\beta_{n} x_{n}+\left(1-\beta_{n}\right) T_{i}^{n} x_{n}\right)-l_{n} x_{n}}{1-l_{n}}
\end{aligned}
$$

$$
\begin{aligned}
= & \frac{\alpha_{n+1} f\left(x_{n+1}\right)}{1-l_{n+1}}-\frac{\alpha_{n} f\left(x_{n}\right)}{1-l_{n}} \\
& +\frac{\left(1-\alpha_{n+1}\right)\left(1-\beta_{n+1}\right) T_{i}^{n+1} x_{n+1}}{1-l_{n+1}} \\
& -\frac{\left(1-\alpha_{n}\right)\left(1-\beta_{n}\right) T_{i}^{n} x_{n}}{1-l_{n}} \\
= & \frac{\alpha_{n+1}}{1-l_{n+1}}\left(f\left(x_{n+1}\right)-T_{i}^{n+1} x_{n+1}\right) \\
& -\frac{\alpha_{n}}{1-l_{n}}\left(f\left(x_{n}\right)-T_{i}^{n} x_{n}\right) \\
& +\left(T_{i}^{n+1} x_{n+1}-T_{i}^{n} x_{n}\right) .
\end{aligned}
$$

We have

$$
\begin{aligned}
&\left\|z_{n+1}-z_{n}\right\|-\left\|x_{n+1}-x_{n}\right\| \\
& \leq \frac{\alpha_{n+1}}{1-l_{n+1}}\left\|f\left(x_{n+1}\right)-T_{i}^{n+1} x_{n+1}\right\| \\
&+\frac{\alpha_{n}}{1-l_{n}}\left\|f\left(x_{n}\right)-T_{i}^{n} x_{n}\right\| \\
&+\left\|T_{i}^{n+1} x_{n+1}-T_{i}^{n+1} x_{n}\right\|+\left\|T_{i}^{n+1} x_{n}-T_{i}^{n} x_{n}\right\| \\
&-\left\|x_{n+1}-x_{n}\right\| \\
&= \frac{\alpha_{n+1}}{1-l_{n+1}}\left(\left\|f\left(x_{n+1}\right)\right\|+\left\|T_{i}^{n+1} x_{n+1}\right\|\right)+\frac{\alpha_{n}}{1-l_{n}} \\
& \quad \times\left(\left\|f\left(x_{n}\right)\right\|+\left\|T_{i}^{n} x_{n}\right\|\right)+\left(h_{n+1}-1\right)\left\|x_{n+1}-x_{n}\right\| \\
&+h_{n}\left\|T_{i} x_{n}-x_{n}\right\| .
\end{aligned}
$$

Using the conclusion of step 1 , by $(C 1), \lim _{n \rightarrow \infty} \| T_{i} x_{n}-$ $x_{n} \|=0$ and $\lim _{n \rightarrow \infty} h_{i n}=1$, and we obtain that $\lim \sup _{n \rightarrow \infty}\left(\left\|z_{n+1}-z_{n}\right\|-\left\|x_{n+1}-x_{n}\right\|\right) \leq 0$.

Hence, by Lemma 3, we have $\lim _{n \rightarrow \infty}\left\|z_{n}-x_{n}\right\|=0$. Consequently,

$$
\lim _{n \rightarrow \infty}\left\|x_{n+1}-x_{n}\right\|=\lim _{n \rightarrow \infty}\left(1-l_{n}\right)\left\|z_{n}-x_{n}\right\|=0 .
$$

Step 3. We prove $\lim _{n \rightarrow \infty}\left\|x_{n}-T_{i}^{n} x_{n}\right\|=0$. From (6), we arrive at

$$
\begin{aligned}
\left\|y_{n}-x_{n}\right\| & \leq\left\|x_{n}-x_{n+1}\right\|+\left\|x_{n+1}-y_{n}\right\| \\
& =\left\|x_{n}-x_{n+1}\right\|+\alpha_{n}\left\|f\left(x_{n}\right)-y_{n}\right\| .
\end{aligned}
$$

Since $\left\{f\left(x_{n}\right)\right\}$ and $\left\{y_{n}\right\}$ are bounded, by (Cl) and $\lim _{n \rightarrow \infty}\left\|x_{n+1}-x_{n}\right\|=0$, we get $\lim _{n \rightarrow \infty}\left\|y_{n}-x_{n}\right\|=0$. As $y_{n}=\beta_{n} x_{n}+\left(1-\beta_{n}\right) T_{i}^{n} x_{n}$, then $\lim _{n \rightarrow \infty}\left\|x_{n}-T_{i}^{n} x_{n}\right\|=0$.

Step 4. We show that $\langle\widehat{x}-f(\widehat{x}), J(\widehat{x}-p)\rangle \leq 0$. Same as [15], let $\hat{x}=\lim _{t \rightarrow 0} x_{t}$ with $x_{t}$ being the fixed point of the contraction 
$x \rightarrow t f(x)+(1-t) T_{i}^{n} x$, where $t \in(0,1)$. That is, $x_{t}=t f\left(x_{t}\right)+$ $(1-t) T_{i}^{n} x_{t}$. Thanks to Lemma 1 , we have

$$
\begin{aligned}
\| x_{t}- & x_{n} \|^{2} \\
= & \left\|(1-t)\left(T_{i}^{n} x_{t}-x_{n}\right)+t\left(f\left(x_{t}\right)-x_{n}\right)\right\|^{2} \\
\leq & (1-t)^{2}\left\|T_{i}^{n} x_{t}-x_{n}\right\|^{2}+2 t\left\langle f\left(x_{t}\right)-x_{n}, J\left(x_{t}-x_{n}\right)\right\rangle \\
\leq & (1-t)^{2} h_{i n}\left\|x_{t}-x_{n}\right\|^{2}+g_{n}(t) \\
& +2 t\left\langle f\left(x_{t}\right)-x_{t}, J\left(x_{t}-x_{n}\right)\right\rangle \\
& +2 t\left\langle x_{t}-x_{n}, J\left(x_{t}-x_{n}\right)\right\rangle,
\end{aligned}
$$

where $g_{n}(t)=\left(2 h_{i n}\left\|x_{t}-x_{n}\right\|+\left\|T_{i}^{n} x_{n}-x_{n}\right\|\right)\left\|T_{i}^{n} x_{n}-x_{n}\right\|$. It follows from step 2 that $\lim _{n \rightarrow \infty} g_{n}(t)=0$. Then from

$$
\begin{aligned}
& \left\langle x_{t}-f\left(x_{t}\right), J\left(x_{t}\right)-x_{n}\right\rangle \\
& \quad \leq \frac{(1-t)^{2} h_{n}-1+2 t}{2 t}\left\|x_{t}-x_{n}\right\|+\frac{1}{2 t} g_{n}(t),
\end{aligned}
$$

we see that

$$
\limsup _{n \rightarrow \infty}\left\langle x_{t}-f\left(x_{t}\right), J\left(x_{t}-x_{n}\right)\right\rangle \leq \frac{t}{2} M_{1},
$$

where $M_{1} \geq 0$, such that

$$
M_{1} \geq\left\|x_{t}-x_{n}\right\|^{2}, \quad \forall t \in(0,1), n \geq 1 .
$$

Then

$$
\limsup _{t \rightarrow 0} \limsup _{n \rightarrow \infty}\left\langle x_{t}-f\left(x_{t}\right), J\left(x_{t}-x_{n}\right)\right\rangle \leq 0 .
$$

So for any $\epsilon>0$, there exists $\delta_{1}>0$. When $t \in\left(0, \delta_{1}\right)$, we get

$$
\limsup _{n \rightarrow \infty}\left\langle x_{t}-f(\widehat{x}), J\left(x_{t}-x_{n}\right)\right\rangle \leq \frac{\epsilon}{2} .
$$

On the other hand, because $x_{t} \rightarrow \widehat{x}$ and $J$ is norm-to-norm uniformly continuous on bounded subsets of $K$, there exists $\delta_{2}>0$, such that when $t \in\left(0, \delta_{2}\right)$, we have

$$
\begin{aligned}
\left|\left\langle f(\widehat{x})-\widehat{x}, J\left(x_{n}-\widehat{x}\right)\right\rangle-\left\langle x_{t}-f(\widehat{x}), J\left(x_{t}-x_{n}\right)\right\rangle\right| \\
\leq\left|\left\langle f(\widehat{x})-\widehat{x}, J\left(x_{n}-\widehat{x}\right)\right\rangle-\left\langle f(\widehat{x})-\widehat{x}, J\left(x_{n}-x_{t}\right)\right\rangle\right| \\
+\mid\left\langle f(\widehat{x})-\widehat{x}, J\left(x_{n}-x_{t}\right)\right\rangle \\
\quad-\left\langle x_{t}-f(\widehat{x}), J\left(x_{t}-x_{n}\right)\right\rangle \mid \\
\leq\left|\left\langle f(\widehat{x})-\widehat{x}, J\left(x_{n}-\widehat{x}\right)-J\left(x_{n}-x_{t}\right)\right\rangle\right| \\
+\left\langle x_{t}-\widehat{x}, J\left(x_{n}-x_{t}\right)\right\rangle \leq \frac{\epsilon}{2} .
\end{aligned}
$$

Choosing $\delta=\min \left\{\delta_{1}, \delta_{2}\right\}, \forall t \in(0, \delta)$, we have

$$
\begin{aligned}
& \left\langle u-\widehat{x}, J\left(x_{n}-\widehat{x}\right)\right\rangle \leq\left\langle x_{t}-u, J\left(x_{t}-x_{n}\right)\right\rangle+\frac{\epsilon}{2}, \\
& \limsup _{n \rightarrow \infty}\left\langle f(\widehat{x})-\widehat{x}, J\left(x_{n}-\widehat{x}\right)\right\rangle \\
& \quad \leq \limsup _{n \rightarrow \infty}\left\langle x_{t}-f(\widehat{x}), J\left(x_{t}-x_{n}\right)\right\rangle+\frac{\epsilon}{2} \leq \epsilon .
\end{aligned}
$$

Since $\epsilon$ is chosen arbitrarily, we get

$$
\limsup _{n \rightarrow \infty}\left\langle u-\widehat{x}, J\left(x_{n}-\widehat{x}\right)\right\rangle \leq 0 .
$$

Hence, we have

$$
\begin{gathered}
\langle\hat{x}-f(\hat{x}), J(\hat{x}-p)\rangle \leq 0, \\
\limsup _{n \rightarrow \infty}\left\langle f(\widehat{x})-\widehat{x}, J\left(x_{n+1}-\widehat{x}\right)\right\rangle \leq 0 .
\end{gathered}
$$

Step 5. We prove that $\lim _{n \rightarrow \infty}\left\|x_{n}-\widehat{x}\right\|=0$. Setting $\xi_{n+1}=$ $\max \left\{\left\langle f(\widehat{x})-\widehat{x}, J\left(x_{n+1}-\widehat{x}\right)\right\rangle\right\}$, we have $\lim _{\sup _{n \rightarrow \infty}} \xi_{n+1} \leq 0$

$$
\begin{aligned}
& \left\|x_{n+1}-\widehat{x}\right\|^{2} \\
& =\| \alpha_{n}\left(f\left(x_{n}\right)-\hat{x}\right)+\left(1-\alpha_{n}\right) \\
& \times\left(\beta_{n}\left(x_{n}-\widehat{x}\right)+\left(1-\beta_{n}\right)\left(T_{i}^{n} x_{n}-\widehat{x}\right)\right) \|^{2} \\
& \leq\left(1-\alpha_{n}\right)^{2}\left[\beta_{n}\left\|x_{n}-\hat{x}\right\|+\left(1-\beta_{n}\right) h_{n}\left\|x_{n}-\widehat{x}\right\|\right]^{2} \\
& +2 \alpha_{n}\left\langle f\left(x_{n}\right)-f(\widehat{x}), J\left(x_{n+1}-\widehat{x}\right)\right\rangle \\
& +2 \alpha_{n}\left\langle f(\widehat{x})-\widehat{x}, J\left(x_{n+1}-\widehat{x}\right)\right\rangle \\
& \leq\left(1-\alpha_{n}\right)^{2} h_{n}^{2}\left\|x_{n}-\hat{x}\right\|^{2}+2 \alpha_{n} \alpha\left\|x_{n}-\hat{x}\right\|\left\|x_{n+1}-\hat{x}\right\| \\
& +2 \alpha_{n}\left\langle f(\widehat{x})-\widehat{x}, J\left(x_{n+1}-\widehat{x}\right)\right\rangle \\
& \leq\left(1-\alpha_{n}\right)^{2}\left\|x_{n}-\widehat{x}\right\|^{2}+\left(1-\alpha_{n}\right)^{2}\left(h_{n}^{2}-1\right)\left\|x_{n}-\widehat{x}\right\|^{2} \\
& +\alpha_{n} \alpha\left(\left\|x_{n}-\widehat{x}\right\|^{2}+\left\|x_{n+1}-\widehat{x}\right\|^{2}\right) \\
& +2 \alpha_{n}\left\langle f(\widehat{x})-\widehat{x}, J\left(x_{n+1}-\widehat{x}\right)\right\rangle .
\end{aligned}
$$

So,

$$
\begin{aligned}
(1- & \left.\alpha_{n} \alpha\right)\left\|x_{n+1}-\widehat{x}\right\|^{2} \\
\leq & \left(1-2 \alpha_{n}+\alpha_{n}^{2}\right)\left\|x_{n}-\hat{x}\right\|^{2}+\left(h_{n}^{2}-1\right)\left\|x_{n}-\widehat{x}\right\|^{2} \\
& +\alpha_{n} \alpha\left\|x_{n}-\widehat{x}\right\|^{2}+2 \alpha_{n}\left\langle f(\widehat{x})-\hat{x}, J\left(x_{n+1}-\widehat{x}\right)\right\rangle \\
\leq & \left(1-2 \alpha_{n}+\alpha_{n} \alpha\right)\left\|x_{n}-\widehat{x}\right\|^{2} \\
& +\left(\alpha_{n}^{2}+h_{n}^{2}-1\right)\left\|x_{n}-\hat{x}\right\|^{2}+2 \alpha_{n} \xi_{n+1},
\end{aligned}
$$

which implies that

$$
\begin{aligned}
& \left\|x_{n+1}-\widehat{x}\right\|^{2} \\
& \leq\left(1-\frac{2(1-\alpha) \alpha_{n}}{1-\alpha_{n} \alpha}\right)\left\|x_{n}-\hat{x}\right\|^{2}+\frac{2(1-\alpha) \alpha_{n}}{1-\alpha_{n} \alpha} \\
& \quad \times\left(\frac{\alpha_{n}+\left(h_{n}-1\right) / \alpha_{n}}{2(1-\alpha)} M_{2}+\frac{1}{1-\alpha} \xi_{n+1}\right) \\
& =\left(1-\gamma_{n}\right)\left\|x_{n}-\widehat{x}\right\|^{2}+\gamma_{n} \delta_{n},
\end{aligned}
$$


where

$$
\begin{gathered}
M_{2}=\sup \left(h_{n}+1\right)\left\|x_{n}-\hat{x}\right\|^{2}, \quad \gamma_{n}=\frac{2(1-\alpha) \alpha_{n}}{1-\alpha_{n} \alpha}, \\
\delta_{n}=\frac{\alpha_{n}+\left(h_{n}-1\right) / \alpha_{n}}{2(1-\alpha)} M_{2}+\frac{1}{1-\alpha} \xi_{n+1} .
\end{gathered}
$$

Since $\left\{x_{n}\right\}$ is bounded, by (C1), (C3), and step 3, we have

$$
\lim _{n \rightarrow \infty} \gamma_{n}=0, \quad \sum \gamma_{n}=\infty, \quad \limsup _{n \rightarrow \infty} \delta_{n} \leq 0
$$

0 .

According to Lemma 2, we deduce that $\lim _{n \rightarrow \infty}\left\|x_{n}-\widehat{x}\right\|=$

Necessity. Since $\hat{x} \in F, \lim _{n \rightarrow \infty}\left\|x_{n}-\widehat{x}\right\|=0, T_{i}$ is uniform Lipschitzian,

$$
\begin{aligned}
& \lim _{n \rightarrow \infty}\left\|T_{i} x_{n}-x_{n}\right\| \\
& \quad \leq \lim _{n \rightarrow \infty}\left[\left\|T_{i} x_{n}-T_{i} \hat{x}\right\|+\left\|T_{i} \hat{x}-\hat{x}\right\|+\left\|\widehat{x}-x_{n}\right\|\right] \\
& \quad \leq \lim _{n \rightarrow \infty}\left\|T_{i} \hat{x}-\hat{x}\right\|+\lim _{n \rightarrow \infty}(L+1)\left\|\widehat{x}-x_{n}\right\| \leq 0 .
\end{aligned}
$$

Hence, the proof of Theorem 4 is completed.

Theorem 5. Under the same conditions as those in Theorem 4, then the sequence $\left\{x_{n}\right\}$ defined by

$$
\begin{gathered}
y_{n}=\beta_{n} x_{n}+\left(1-\beta_{n}\right) T_{n}^{n} x_{n}, \quad n \geq 0, \\
x_{n+1}=\alpha_{n} f\left(x_{n}\right)+\left(1-\alpha_{n}\right) y_{n}, \quad n \geq 0,
\end{gathered}
$$

converges strongly to $\hat{x} \in F$, if and only if $\lim _{n \rightarrow \infty} \| T_{n} x_{n}-$ $x_{n} \|=0$ holds. And $\hat{x}$ is a solution of the following variational inequality:

$$
\langle\widehat{x}-f(\widehat{x}), J(\widehat{x}-p)\rangle \leq 0, \quad \forall p \in F .
$$

Proof. The proof is the same as that of Theorem 4 . We can just use $T_{n}^{n}, h_{n n}$ to take the place of $T_{i}^{n}, h_{i n}$.

Theorem 6. Let $\left\{T_{i}\right\}_{i=1}^{N}$ be a finite family of asymptotically nonexpansive mappings with the coefficients $h_{\text {in }}: \lim _{n \rightarrow \infty} h_{\text {in }}=1$ and $\left\{T_{n}\right\}=\left\{T_{n(\bmod N)}\right\}$. The rest of the conditions are the same as those in Theorem 4 . Then the sequence $\left\{x_{n}\right\}$ defined by (38) converges strongly to $\widehat{x} \in F$, if and only if $\lim _{n \rightarrow \infty} \| T_{n} x_{n}-$ $x_{n} \|=0$ holds. And $\hat{x}$ is a solution of the following variational inequality:

$$
\langle\widehat{x}-f(\widehat{x}), J(\widehat{x}-p)\rangle \leq 0, \quad \forall p \in F .
$$

Proof. This is a special case of Theorem 5.

Remark 7. If $\left\{T_{i}\right\}_{i=1}^{N}$ is a finite family of nonexpansive mappings in Theorem 6 , then it is the main result in reference [8]. So our results in this paper extend and improve the recent results of many other authors (e.g., see $[1,8,17,19])$ in different ways, such as from nonexpansive mappings to the more general class of asymptotically nonexpansive mappings and from finite family mappings to infinite family mappings. And the methods here are different from the previous ones.

\section{Conflict of Interests}

The author declares that there is no conflict of interests regarding the publication of this paper.

\section{Acknowledgments}

The author would like to thank the editors and referees for many useful comments and suggestions for the improvement of the paper. This work was partially supported by the Natural Science Foundation of Zhejiang Province (LY14A010011) and the National Natural Science Foundation of China (11271330).

\section{References}

[1] K. Goebel and W. A. Kirk, "A fixed point theorem for asymptotically nonexpansive mappings," Proceedings of the American Mathematical Society, vol. 35, pp. 171-174, 1972.

[2] S. H. Khan and W. Takahasi, "Approximating common fixed points of two asymptotically nonexpanisve mappings," Scientiae Mathematicae Japonicae, vol. 53, pp. 143-148, 2001.

[3] Z.-H. Sun, "Strong convergence of an implicit iteration process for a finite family of asymptotically quasi-nonexpansive mappings," Journal of Mathematical Analysis and Applications, vol. 286, no. 1, pp. 351-358, 2003.

[4] H.-K. Xu and R. G. Ori, "An implicit iteration process for nonexpansive mappings," Numerical Functional Analysis and Optimization, vol. 22, no. 5-6, pp. 767-773, 2001.

[5] N. Shahzad and A. Udomene, "Approximating common fixed points of two asymptotically quasi-nonexpansive mappings in Banach spaces," Fixed Point Theory and Applications, vol. 2006, Article ID 18909, 2006.

[6] N. Shahzad and H. Zegeye, "Strong convergence of an implicit iteration process for a finite family of generalized asymptotically quasi-nonexpansive maps," Applied Mathematics and Computation, vol. 189, no. 2, pp. 1058-1065, 2007.

[7] A. R. Khan, A.-A. Domlo, and H. Fukhar-ud-din, "Common fixed points Noor iteration for a finite family of asymptotically quasi-nonexpansive mappings in Banach spaces," Journal of Mathematical Analysis and Applications, vol. 341, no. 1, pp. 1-11, 2008.

[8] L. C. Zhao, "Viscosity approximation of fixed points for a finite family of nonexpansive mappings," Journal of Acta Mathematica Sinica, vol. 31, pp. 599-607, 2008.

[9] Y.-C. Lin, N.-C. Wong, and J.-C. Yao, "Strong convergence theorems of Ishikawa iteration process with errors for fixed points of lipschitz continuous mappings in Banach spaces," Taiwanese Journal of Mathematics, vol. 10, no. 2, pp. 543-552, 2006.

[10] L.-C. Zeng and J.-C. Yao, "Stability of iterative procedures with errors for approximating common fixed points of a couple of $q$-contractive-like mappings in Banach spaces," Journal of Mathematical Analysis and Applications, vol. 321, no. 2, pp. 661674, 2006.

[11] Y. Yao, J.-C. Yao, and H. Zhou, "Approximation methods for common fixed points of infinite countable family of nonexpansive mappings," Computers and Mathematics with Applications, vol. 53, no. 9, pp. 1380-1389, 2007. 
[12] W. Cholamjiak and S. Suantai, "A new hybrid algorithm for a countable family of quasi-nonexpansive mappings and equilibrium problems," Journal of Nonlinear and Convex Analysis, vol. 12, pp. 381-398, 2011

[13] S. Plubtieng and K. Ungchittrakool, "Approximation of common fixed points for a countable family of relatively nonexpansive mappings in a Banach space and applications," Nonlinear Analysis: Theory, Methods and Applications, vol. 72, no. 6, pp. 2896-2908, 2009.

[14] L.-C. Zeng and J.-C. Yao, "Implicit iteration scheme with perturbed mapping for common fixed points of a finite family of nonexpansive mappings," Nonlinear Analysis: Theory, Methods and Applications, vol. 64, no. 11, pp. 2507-2515, 2006.

[15] G. Marino and H.-K. Xu, "A general iterative method for nonexpansive mappings in Hilbert spaces," Journal of Mathematical Analysis and Applications, vol. 318, no. 1, pp. 43-52, 2006.

[16] Y.-H. Wang and Y.-H. Xia, "Strong convergence for asymptotically pseudocontractions with the demiclosedness principle in Banach spaces," Fixed Point Theory and Applications, vol. 2012, article 45, 2012.

[17] Y. Wang and W. Xuan, "Convergence theorems for common fixed points of a finite family of relatively nonexpansive mappings in Banach spaces," Abstract and Applied Analysis, vol. 2013, Article ID 259470, 7 pages, 2013.

[18] Y. Wang and C. Wang, "Convergence of a new modified ishikawa type iteration for common fixed points of total asymptotically strict pseudocontractive semigroups," Abstract and Applied Analysis, vol. 2013, Article ID 319241, 7 pages, 2013.

[19] Y. J. Cho, S. M. Kang, and X. Qin, "Approximation of common fixed points of an infinite family of nonexpansive mappings in Banach spaces," Computers and Mathematics with Applications, vol. 56, no. 8, pp. 2058-2064, 2008.

[20] H. K. Xu, "Vistosity approximation methods for nonexpansive mappings," Journal of Mathematical Analysis and Applications, vol. 298, pp. 279-291, 2004.

[21] T. Suzuki, "Strong convergence of Krasnoselskii and Mann's type sequences for one-parameter nonexpansive semigroups without Bochner integrals," Journal of Mathematical Analysis and Applications, vol. 305, no. 1, pp. 227-239, 2005. 


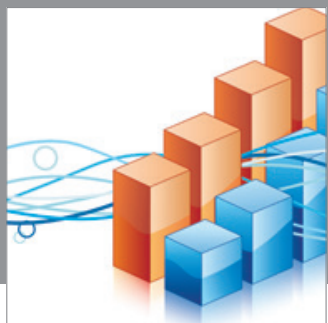

Advances in

Operations Research

mansans

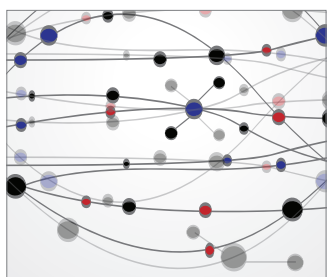

The Scientific World Journal
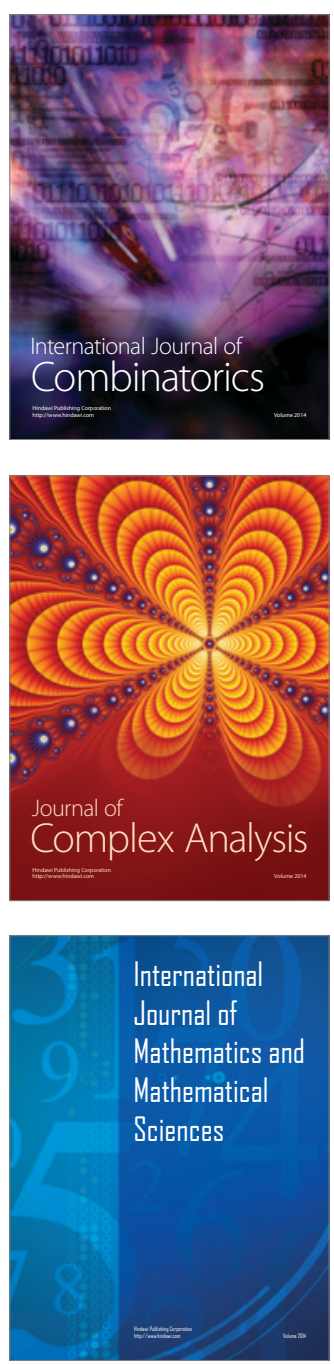
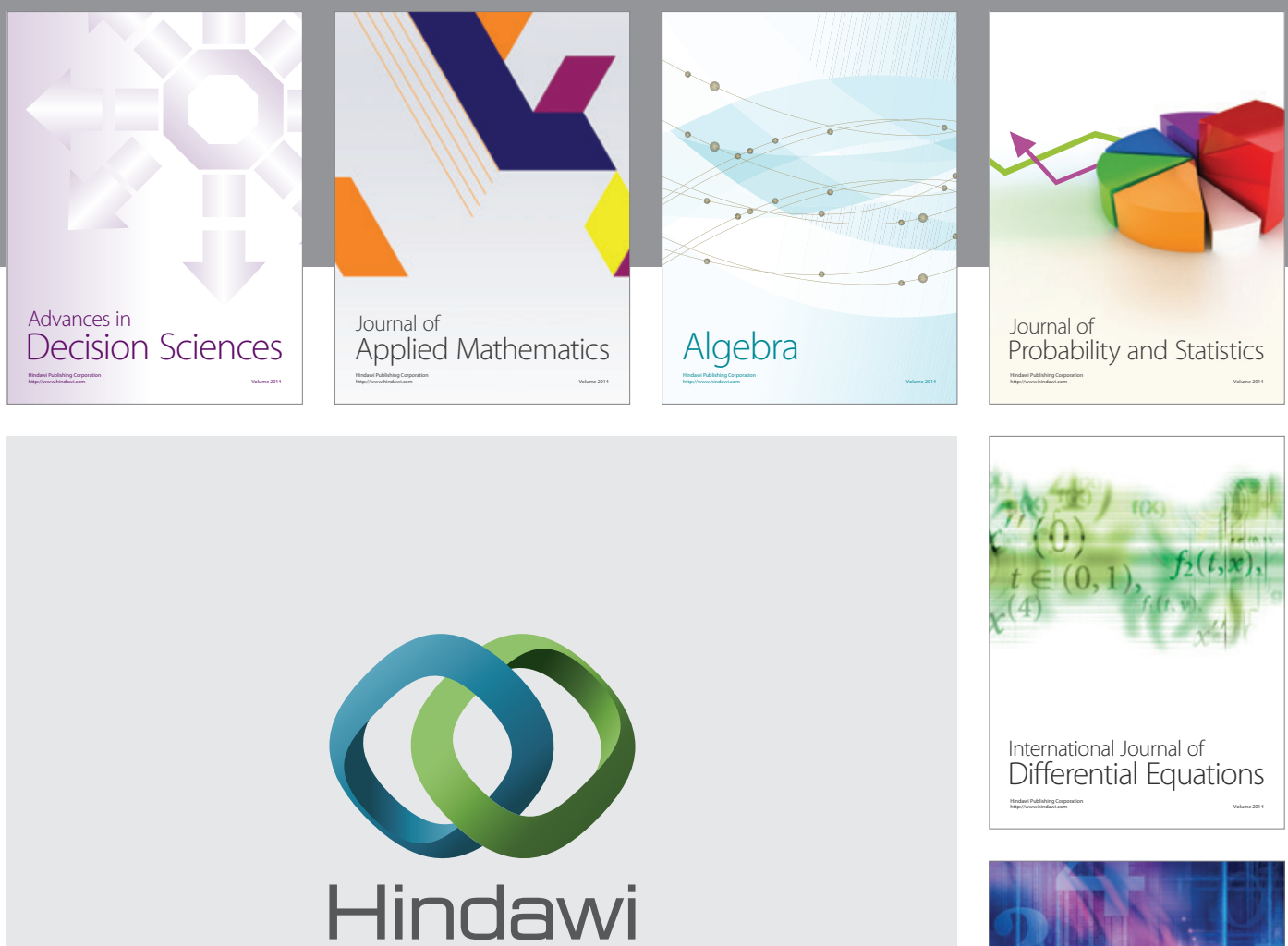

Submit your manuscripts at http://www.hindawi.com
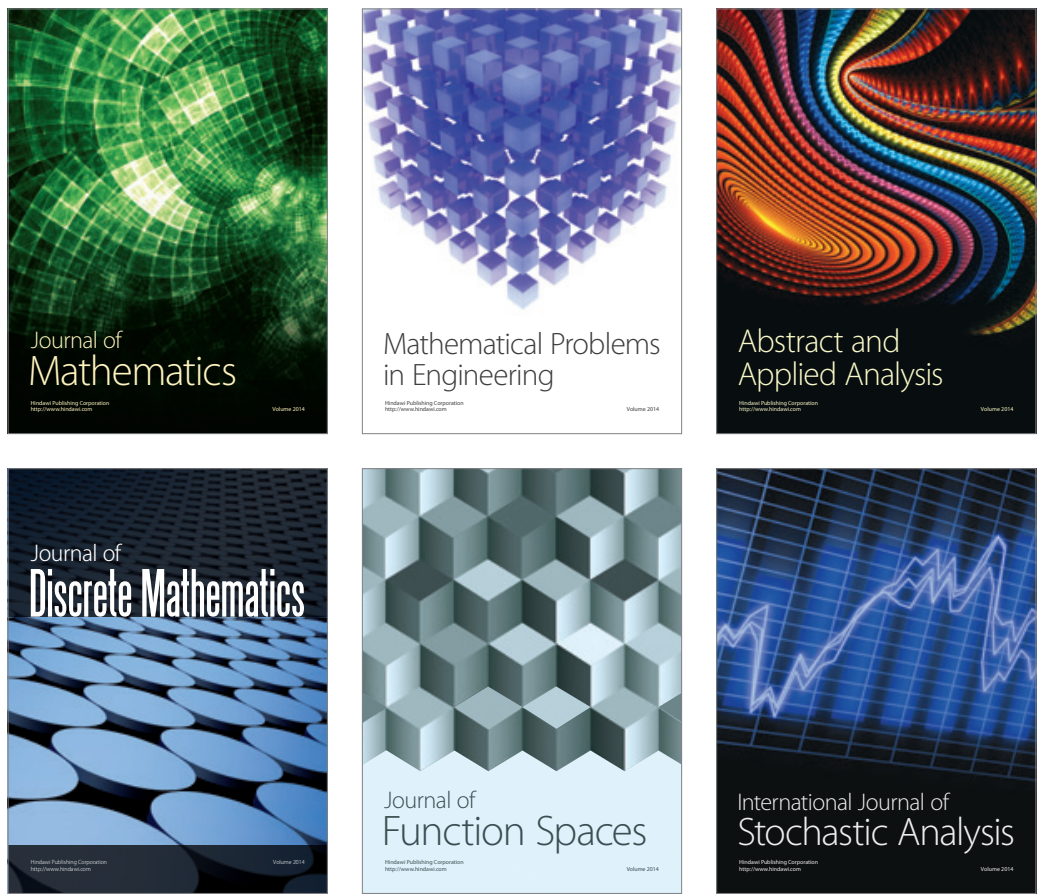

Journal of

Function Spaces

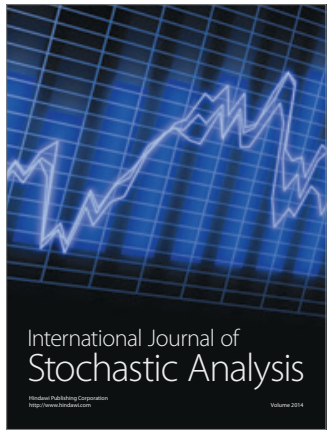

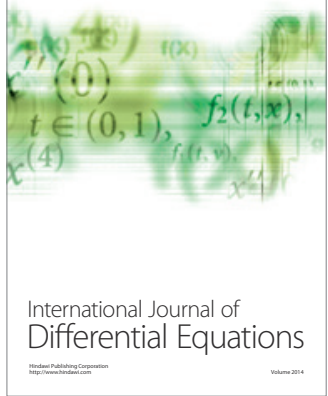
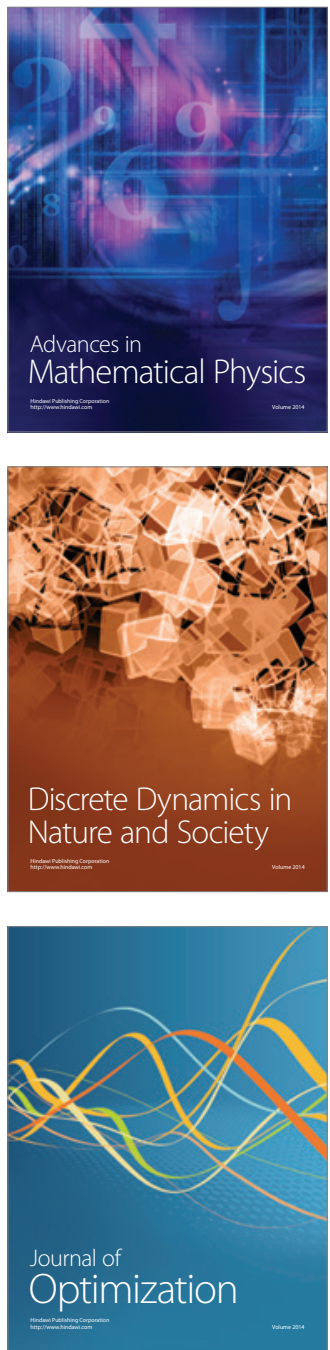